\title{
Alguns aspectos civis acerca da utilização de células-tronco
}

\author{
Regiani Cristina Ghizelini ${ }^{1}$ \\ José Monfroi ${ }^{2}$ \\ Maucir Pauletti ${ }^{3}$
}

\begin{abstract}
Resumo
Trata-se de um estudo sobre os reflexos no ordenamento jurídico, em especial no âmbito civil, na utilização de células-tronco embrionárias e adultas para fins terapêuticos. A utilização das células-tronco adultas é pacífica e equiparável às técnicas de transplante de órgãos. Quanto às embrionárias, apurou-se ser a melhor técnica o uso das provenientes de embriões excedentários. É condenável, sobremaneira, a clonagem destas, mesmo que para fins terapêuticos, bem como a produção de embriões com fim único de retirar estas células para pesquisas e experimentos terapêuticos. No âmbito cível não podem ser consideradas, por si sós, sujeitos de direitos, sendo plenamente viável a utilização em pesquisas científicas humanitárias.
\end{abstract}

Palavras-Chave: Células-tronco; Espécies; Utilização; Responsabilidades; Reflexos Jurídicos.

\section{Introdução}

O presente trabalho visa a uma análise dos reflexos que o surgimento de novas biotecnologias podem apresentar no cotidiano das pessoas, com implicações não só nos aspectos morais, éticos e religiosos, mas também, e principalmente, no jurídico.

A controvérsia toda se inicia com um dos temas mais debatidos ao longo dos tempos, e que até o presente momento não logrou solução - e quiçá, nunca se consiga chegar a uma resposta definitiva -, que é o seguinte questionamento: "quando a vida começa"?

Assim, após décadas de estudos, biólogos, médicos e cientistas não conseguiram até hoje dizer quando a vida começa. O que existem são inúmeras teorias, que ditam que o início da vida pode se dar ora com a fecundação, ora com a formação do tecido nervoso

1 Graduação em Direito pela Universidade Estadual de Londrina - UEL. Assessora Jurídica (Assistente 1-C) do Ministério Público do Estado do Paraná. E-mail: recrisghizelini@bol.com.br.

2 Professor Orientador José Monfroi: Graduação em Filosofia (FUCMT/MS); Mestrado em Educação (UFMS); Doutorado em Educação (UNESP/Marília/SP). E-mail: jmanfroi@ucdb.br

3 Professor Orientador Maucir Pauletti: Graduação em Direito, professor, especialista em direito civil e empresarial, mestre em direito das obrigações, filósofo e pesquisador. E-mail: maucir@ucdb.br 
(após o 14. dia), ora com a nidação ${ }^{4}$, ora com o início dos batimentos cardíacos, ou ainda, com o nascimento, porém, nenhum deles com precisão e certeza.

Se por um lado não é possível dizer quando a vida começa, o mesmo não ocorre com a definição de morte. Para o direito pátrio, a morte é definida como o fim da atividade cerebral. Todavia, se o final da vida se dá com a morte encefálica, por oposto deveria então a vida iniciar-se também com esta, mas este mesmo critério como único e indiscutível, não é viável, haja vista que outros aspectos, tanto ou mais relevantes, devem ser levados em consideração para se dizer se existe vida ou não.

Dessa forma, por não se tratar de uma questão plenamente resolvida, criou-se uma enorme discussão acerca da utilização das células-tronco, em especial em relação às embrionárias, pois a partir do momento em que se opta por um dos critérios acima, esta opção refletirá, inevitavelmente, no ordenamento jurídico e nas relações sociais.

\section{Células-tronco}

O tema em exposição vem sendo debatido de longa data, sendo que entre uma das primeiras legislações brasileiras a cuidar do organismo geneticamente modificado - OGM e do conceito de engenharia genética (art. 3ำ, incisos IV e V), além de abordar a manipulação genética de células germinais humanas, a Lei n. 8.974 de janeiro de $1995^{5}$, - que proibia a produção, o armazenamento ou manipulação de embriões humanos destinados a servir como material biológico disponível (art. 8o, incisos II e IV), chegando a prever severas penas , e o estágio atual, decorreram mais de 10 (dez) anos.

Assim, somente em 24 de março de 2005 foi promulgada a Lei n.o 11.105 (Lei de Biossegurança), a qual além de regulamentar a utilização e manipulação de organismos geneticamente modificados, passou a permitir, mediante consentimento, a utilização de embriões excedentários ${ }^{6}$ para pesquisas científicas, desde que preenchidos os requisitos legais.

\footnotetext{
4 A nidação é a implantação, a fixação do blastocisto (pré-embrião) no endométrio (mucosa que reveste o útero).

5 Modificada pela Medida Provisória 2.191-9 de agosto de 2001 e regulamentada pelo Decreto 1.752 de dezembro de 1995.

6 São aqueles embriões que sobraram após a implantação no útero da mulher e que vão ser congelados.
} 


\subsection{Conceito. espécies. formas de utilização}

O conceito de células-troncos, também chamadas de células-mãe ou progenitoras, é dado pela biologia como sendo aquelas que devido à sua plasticidade são capazes de gerar os mais diferentes tipos de células, inclusive de fazer cópias idênticas de si mesmas, bem como de reconstruir os tecidos danificados por doenças, má-formação ou lesões.

As células-tronco podem ser classificadas em: embrionárias e adultas ou maduras. Estas são células-tronco hematopoéticas ${ }^{7}$, cujas principais fontes são a medula óssea e o sangue de cordão umbilical. Já as primeiras são definidas por sua origem e são derivadas do estágio do blastocisto ${ }^{8}$ do embrião, normalmente gerados em clínicas de reprodução humana, onde o casal, após a fertilização in vitro e a implantação de número suficiente para gerar a criança - na maioria dos países que permitem, doa os excedentes para a pesquisa com fins terapêuticos.

Estas células-mãe podem ser utilizadas com as mais diversas finalidades, porém, o mais comum era até então, na fecundação assistida, visando a formação de embriões que, após implantados no útero da mulher, gerariam a tão esperada criança, não se preocupando com os sobressalentes, pois até a edição da Lei de Biossegurança a sua manipulação, independente da finalidade (incluindo-se a clonagem reprodutiva e a terapêutica) era proibida.

Todavia, as ciências biológicas não são estáticas, mas dinâmicas e a evolução fez surgir novas biotecnologias, modificando a vertente reprodutiva, passando em alguns países a serem produzidos embriões com finalidade única de pesquisas científicas, visando a descoberta de novas técnicas de tratamento e de curas de doenças, pois não basta gerar novos seres humanos, é preciso que estes tenham uma vida digna, e isto inclui direito a uma vida saudável.

Assim, a despeito de todo o poder curativo das células-tronco embrionárias preconizadas pelos cientistas, bem como da liberação pelo ordenamento jurídico para a

\footnotetext{
São células primitivas que possuem a capacidade de auto-renovação e diferenciação em diversos tipos de células, sendo as responsáveis pela manutenção da hematopoese, ou seja, originam as células sangüíneas adultas.

8 É o conjunto de células no estágio inicial da formação do embrião.
} 
utilização em pesquisas, estas não se iniciaram em seres humanos ${ }^{9}$, sendo restritas às cobaias de laboratório, uma vez que a veracidade dessa "cura milagrosa", não pode ser ainda aferida. E mais, como toda nova terapia curativa, as pesquisas deverão ser longas e árduas até que os resultados possam atestar seguramente seus efeitos regenerativos.

Por outro lado, as pesquisas com células-tronco adultas ou maduras, introduzidas em voluntários, tem apresentado bons resultados curativos, sem gerar qualquer forma de repulsa por segmentos da sociedade, sendo a sua regulamentação pelo Direito muito mais fácil e menos dolorosa, tanto que, hoje, já existem bancos de sangue de cordão umbilical e placenta.

Os bancos de sangue de cordão umbilical e placentários foram criados com a finalidade de manter células progenitoras que são coletadas após o nascimento, e, em seguida, armazenadas através da técnica da criopreservação ${ }^{10}$, visando, primordialmente, aos transplantes de medulas ósseas. Esses bancos eram, inicialmente, privados ${ }^{11}$, porém os altos custos de coleta, armazenamento e manutenção estavam inviabilizando a existência de amostras em larga escala, no intuito de se atender a crescente demanda, em especial após a divulgação de resultados positivos na sua utilização para a cura de certas doenças.

Diante disso, o Ministério da Saúde, através da Portaria Ministerial n. 2.381, de 28.10.2004, criou oficialmente, em âmbito nacional, a Rede Brasilcord ${ }^{12}$, que regulamenta a operação dos bancos de sangue de cordão umbilical públicos, mantendo um banco de doadores de medula óssea que deve chegar a um número suficiente para acabar com as filas do transplante. Além disso, existe a possibilidade de intercambiar amostras com os bancos

9 No Brasil não se têm notícias comprovadas do início das pesquisas em seres humanas, fato que já ocorre em outros países como noticiado recentemente no Programa "Fantástico" da Rede Globo de Televisão, do dia 03.12.2006.

10 A técnica consiste em o cordão umbilical ser pinçado (lacrado com uma pinça) e separado do bebê, cortando a ligação entre o bebê e a placenta. A quantidade de sangue (cerca de 70 a $100 \mathrm{ml}$ ) que permanece no cordão e na placenta é drenada para uma bolsa de coleta. Já no laboratório de processamento, as células-tronco são separadas e preparadas para o congelamento. Após processo de depuração, a amostra é congelada a - 90 (noventa graus negativos) e, em seguida, armazenada em tanques de nitrogênio a -180 (cento e oitenta graus negativos). Dentre eles, podemos citar o cryopraxis (considerado o maior banco particular da América Latina) e o cordvida.

12 Participaram deste grupo os seguintes serviços: INCA - CEMO; Hemocentro de Ribeirão Preto - SP; UNICAMP - Campinas - SP; Hospital Albert Einstein - São Paulo - SP, além de outros que venham a integrar a Rede pública. In: INSTITUTO NACIONAL DE CÂNCER. Banco de sangue de cordão umbilical e placentário (BSCUP). Disponível em: http://www.inca.gov.br/conteudo_view.asp>. Acesso em: 12 fev. 2007. 
estrangeiros participantes da rede mundial Netcord, aumentando as chances de se encontrar células compatíveis para transplante.

\subsection{Obrigações jurídicas. Responsabilidades}

O uso de células-tronco embrionárias e adultas implica em uma grande responsabilidade por parte dos profissionais que fazem a sua manipulação e, nessa esteira, o ordenamento jurídico brasileiro, com seu regramento veio com a intenção não de coibir a utilização dessas novas técnicas, mas regulamentá-las de forma ética e responsável, impedindo que sejam cometidos abusos condenáveis sob todos os aspectos.

A antiga Lei de Biossegurança n. ei 8.974/95 (Art. 13), revogada pela atual, a Lei n.o 11.105/2005, proibia expressa e totalmente a manipulação de células germinais humanas ${ }^{13}$, sendo extremamente restritiva a sua utilização em pesquisas científicas.

Todavia com o advento da nova Lei de Biossegurança a manipulação genética de embriões excedentários com a finalidade de desenvolver técnicas e métodos curativos para doenças até então consideradas de cura improvável pela ciência, passou a ser permitido, desde que, a sua utilização seja precedida "em qualquer caso do consentimento dos

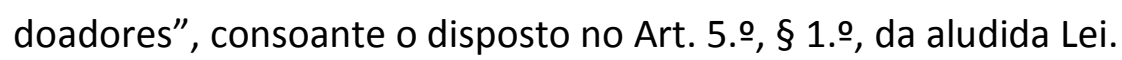

E mais, além desse consentimento, exige-se que estes embriões não utilizados sejam inviáveis, ou seja, as células-mãe embrionárias destinadas a pesquisas científicas devem ser inservíveis ao fim a que se destinavam: a implantação bem sucedida no útero da mulher e seu desenvolvimento, com a conseqüente formação de um novo ser. Ou ainda, alternativamente, que estejam congelados há mais de 03 (três) anos na data da publicação da Lei ou a contar esse prazo a partir da promulgação da Lei e do seu congelamento.

Por fim, a norma supra exige um rigoroso controle na manipulação desse material genético, a cargo dos Comitês de Ética e Pesquisa e da CTNBio - Comissão Técnica Nacional de Biossegurança, vedando, ainda, a comercialização desse material genético, sob pena de incidir nas cominações do Art.15 da Lei 9.434/97 ${ }^{14}$.

\footnotetext{
13 Que são aquelas células reprodutivas dos seres vivos.

14 Lei que regulamenta o transplante de órgão e considera crime a sua comercialização.
} 


\section{Embriões. Aspectos biológicos: formação, congelamento e manutenção}

Os embriões, biologicamente falando, são formados não apenas pela fecundação do óvulo pelo espermatozóide, ou seja, este encontro não é suficiente para a formação do embrião, sendo necessário que a célula formada inicie a sua divisão celular, para só então se falar em sua existência.

Mas, o embrião propriamente dito, só se forma após o 14.ำ dia da fecundação, pois no período anterior, do zigoto ${ }^{15}$ ao blastocisto, o que ocorre é a formação do pré-embrião.

A teoria do pré-embrião foi criada pelo Relatório de Warnock sobre Fertilização e Embriologia ${ }^{16}$, publicado no Reino Unido, em 1984, segundo o qual, somente a partir do 14.을 dia se inicia o desenvolvimento do sistema nervoso central, sendo no período anterior, a multiplicação das células, tão-somente um emaranhado destas, sem perspectiva de se tornar um ser Humano.

Esse entendimento é o adotado pelo Conselho Federal de Medicina em sua Resolução n. 1358/92, Item VI, n. 3, bem como por grande parte dos biólogos, cientistas e médicos de escol.

Segundo Krell (2006, p.132), essa distinção entre pré-embrião e embrião é o ponto crucial para o enfrentamento da polêmica utilização das "sobras embrionárias" provenientes da fertilização in vitro em pesquisas e no desenvolvimento de novas terapias com célulastronco embrionárias.

O congelamento dos embriões, ou melhor dizendo, dos pré-embriões, não utilizados ou excedentes é feito entre o terceiro e o sexto dia após a fecundação, pois após o sexto dia este não sobrevive mais no meio de cultura em que ocorreu a fecundação e divisão celular.

Para sua conservação é utilizada uma técnica chamada de "crioprotetiva", através da qual estes vão sendo gradativamente congelados em nitrogênio líquido até chegarem a uma temperatura de -1960 C (cento e noventa e seis graus negativos).

15 Zigoto, segundo o Dicionário Aurélio, é a célula reprodutora resultando da fusão de dois gametas de sexo oposto, ou seja, da fusão do óvulo (feminino) com o espermatozóide (masculino).

16 O Governo da Grã-Bretanha, em 1982, constituiu uma comissão sob a presidência de Mary Warnock, com a finalidade de estudar e analisar temas relativos à reprodução assistida, que foi publicado em 1984. In: KRELL, Olga Jubert Gouveia. Reprodução humana assistida e filiação civil: Princípios éticos e jurídicos. Curitiba:Juruá, 2006. p. 132. 
Dessa forma, os pré-embriões podem permanecer congelados por longos períodos, sem que sofram qualquer tipo de alteração em sua estrutura. Isto implica dizer que, estes não possuem prazo de validade, pois como se tem noticiado já houve episódios de casais que após mais de dez anos resolveram ter outro filho, utilizando-se, para tanto, de embriões excedentes e com grande sucesso.

Vale dizer, estes não perdem qualidade por haverem ficado congelados por longos períodos, embora haja recomendações para que não sejam utilizados após certo tempo. $\mathrm{Na}$ verdade o que vai torná-lo imprestável ou não são as intercorrências que podem surgir durante o seu descongelamento e manipulação.

\subsection{Conceito. Manipulação. Utilização em pesquisas científicas (clonagem terapêutica)}

O embrião pode ser conceituado como sendo a individualidade que integra a espécie humana em seus primeiros estágios de desenvolvimento.

A sua manipulação, primordialmente, ocorre para a fecundação assistida, sendo os excedentes congelados e, à partir da Lei de Biossegurança, estes poderão ser utilizados para pesquisas científicas.

No que concerne à clonagem, a Lei de Biossegurança em seu Art. 6.ำ proibiu genericamente a clonagem humana, inclusive considerando crime a sua realização (Art. 26), não fazendo qualquer distinção quanto à sua finalidade, ou seja, se para fins reprodutivos entenda-se formação de seres geneticamente iguais -, ou para formação de tecidos e órgãos, chamada neste caso de clonagem terapêutica.

Todavia, a despeito dessa omissão da Lei, moral e eticamente, parece ser uma conduta reprovável, em face da grande quantidade de embriões de reserva que se encontram congelados e que nunca serão usados, sendo por isso, o melhor destino para estes, a sua utilização em pesquisas do que serem descartados como lixo hospitalar.

Nesse diapasão, vale lembrar, ainda, a existência do Projeto de Lei n.o 6.006 de 2005, de autoria do Deputado Paulo Baltazar, que visa a modificação da Lei no 11.105/05, a fim de se permitir o uso de células progenitoras, obtidas por meio da clonagem terapêutica.

Saliente-se que o referido Projeto de Lei visa a por fim à lacuna deixada pela Lei de Biossegurança quando proibiu genericamente a clonagem humana, passando, então, a fazer 
a distinção entre a clonagem reprodutiva e terapêutica e, manifestando-se, expressamente, apenas contra a reprodutiva, devendo, por oportuno a clonagem terapêutica ser liberada, sob a fiscalização dos Comitês de Ética.

A justificativa para a sua liberação é de que a restrição à utilização das sobras limitaria, em muito, o grande potencial que elas têm no tratamento de doenças e disfunções do ser humano, bem como de que a uso dessa técnica, estaria eliminando por completo o problema da rejeição de enxertos de células do embrião clonado para o paciente, uma vez que suas células seriam imediatamente compatíveis.

\subsection{Repercussão no âmbito moral, religioso, ético e jurídico}

Não há dúvidas quanto ao potencial das células-tronco e aos novos rumos que elas podem dar ao futuro da humanidade, mas isso não é tão simples e, como toda nova biotecnologia, acarreta intrincadas discussões com ferrenhos posicionamentos, uns pró e outros contra. As religiões e seus seguidores, inclusive, vêem com bons olhos as pesquisas com as células-tronco adultas ou maduras, o mesmo não ocorrendo com as provenientes de embriões.

O grande dilema é que, segundo os cientistas, o melhor tipo de célula-tronco se encontra no embrião, e aí entra a discussão de início da vida, tendo as Igrejas se posicionado radicalmente - e sob o argumento de defender o direito à vida - contra a utilização destas células.

A Igreja Católica tem uma posição firme não só contra a utilização de embriões para pesquisas, mas primordialmente contra a própria fertilização in vitro, além das técnicas de clonagem terapêutica e, evidentemente, contra a clonagem humana.

Do ponto de vista do espiritismo, a utilização de embriões em pesquisas também é rejeitada. Segundo a filosofia kardecista, basta o magnetismo dos pais e o desejo do espírito para que se dê a reencarnação. As revelações espirituais dizem que o espírito reencarnante se une ao corpo no momento da concepção, isto é, no instante da formação do zigoto ou célula-ovo, e só o espírito tem o poder de agregar matéria. Portanto, para os espiritualistas, esse processo pode ocorrer mesmo no laboratório. Em princípio, consideram que descartar um embrião fertilizado fora do útero da mãe é o mesmo que promover um aborto. Entretanto, há outra revelação: a de que nem todos os embriões têm um espírito ligado. 
Mas como saber se um embrião congelado numa clínica de fertilização tem ou não um espírito ligado? Dessa forma, temos que esse posicionamento não é simples assim, é necessário pesquisar para se chegar a conclusão de que o embrião vai se tornar um ser humano ou não, e conseqüentemente, haja um espírito a ele ligado. Assim, até que isto aconteça, ou seja, até que a certeza venha, os espíritas se posicionam pela utilização das células- tronco adultas.

Já o judaísmo possui uma concepção diferenciada sobre o tema, pois aplica status diferente ao embrião, ao feto e ao recém-nascido. À medida que a gravidez evolui, o organismo adquire um status superior. No começo, até 40 dias depois da fecundação, é como se o embrião fosse apenas água e não vida. Tanto que a pesquisa com embriões, inclusive com uso de células-tronco, bem como procedimentos de clonagem terapêutica, são permitidos em Israel. O médico Salmo Raskim (2006), membro da comunidade judaica, conta que a maioria dos sábios judeus pensa desta maneira, mas é importante ressaltar que não se trata de uma postura unânime. Há posições contrárias de judeus ortodoxos que, assim como os católicos, acreditam que a vida começa mesmo no momento da fecundação.

Do exposto, depreende-se, mais uma vez, que o tema é conflituoso até mesmo entre as Igrejas, religiões e filosofias espirituais, de modo que antes de se legislar regulamentando o uso das células-tronco embrionárias, seja apenas para pesquisas científicas ou também para clonagem terapêutica, a sociedade, os religiosos, legisladores e operadores do direito, terão muito que discutir até se chegar "próximo" a um consenso.

\section{Aspectos civis na utilização das células-tronco. Do direito à vida}

Para se aferir os reflexos do uso das células-tronco na esfera civil, preliminarmente, há que se fazer o enfrentamento da tormentosa questão do início da vida, adotando um critério ou teoria, como ponto de partida para se definir a existência de vários direitos, tais como, vida, integridade, filiação, sucessão, dentre outros.

Há várias teorias acerca do início da vida, sendo que para aqueles que defendem o início da vida a partir da concepção, todas as células estariam direcionadas, desde fecundação, para a formação de um ser humano, sendo, portanto, inconcebível a escolha de uma etapa para passar a considerá-lo embrião, condição esta que deveria ser-lhe atribuída desde a fecundação. Já para os que defendem a teoria do pré-embrião, preconizada no 
famoso relatório de Warnock, até o 14ㅇ (décimo quarto) dia o zigoto não apresenta sistema nervoso central, e, portanto, não passaria de um emaranhado de células, ou seja, de unidade inacabada da vida humana.

Mas, a despeito das concepções teóricas acima mencionadas, outro fator há que ser levado em consideração, qual seja, a implantação desse pré-embrião em um útero para que se desenvolva e possa a vir a nascer com vida. Não dá para se falar em ser humano somente partindo-se da existência seja de um pré-embrião ou de um embrião, pois embora a fecundação possa ocorrer em laboratório, a sobrevivência desse embrião e o seu desenvolvimento não podem ocorrer fora do útero materno, que é o único local em que este pode se fixar e vir a se tornar um ser humano.

Deve-se ter em mente que, um embrião criado em laboratório pode ser mantido criopreservado por anos a fio, mas nunca se tornará um ser humano na sua acepção lata, pois não se completaram as suas fases mínimas necessárias, incluindo aí a nidação, que consiste na implantação do concepto no endométrio ${ }^{17}$, sendo que é a partir desse momento que se inicia a formação dos vasos sangüíneos e demais sistemas ${ }^{18}$.

Dessa forma, partindo-se dos conceitos esposados pela teoria do pré-embrião, somando-se a este o da Nidação, tem-se que o início da vida deve ser considerado a partir da implantação do pré-embrião e sua fixação na mucosa do útero, pois só assim estará apto a se tornar um ser humano completo, o que não significa excluí-lo da proteção do ordenamento jurídico.

Assim, temos que o pré-embrião possui uma existência a ser protegida pelo Direito, como o faz a Lei de Biossegurança, mas não se pode falar ainda que exista vida propriamente dita, e, portanto, que este seja sujeito de direitos e obrigações, com direito ao nome, perfilhação, sucessão, dentre outros.

Por seu turno, o ordenamento jurídico brasileiro não conceituou o início da vida, tendo o Código Civil em seu Art. 2. ${ }^{\circ}$, feito referência tão-somente à concepção, ao ressalvar o direito do nascituro, deixando claro tratar-se do embrião que venha a lograr nascimento com vida ou que possa vir a ser uma pessoa, porém, sem esclarecer se implantado no útero (proveniente da fecundação assistida) ou ali presente naturalmente (reprodução natural).

17 Endométrio é a mucosa que reveste o útero e onde o embrião vai se fixar para se desenvolver.

18 Posicionamento este reforçado pelas explicações dos médicos do Centro de Reprodução Humana de Londrina. 
Diante disso, surgiram várias correntes, dentre as quais, a Concepcionalista que, adotando uma interpretação sistemática, socorreu-se do Art. 5.ํ da Carta Magna para defender os direitos do nascituro - incluindo aí a vida, integridade física, dignidade, dentre outros -, estendendo essas prerrogativas aos embriões oriundos da fertilização in vitro. Já a corrente Natalista, por entender que o nascituro constitui uma mera expectativa de vida, o qual sem uma gestação não existe a possibilidade de vir a existir, defende uma interpretação literal do Art. 2.o do CC, pregando que a aquisição de direitos somente ocorrerá do nascimento com vida.

Nesse sentido Krell (2006, p. 132) entende que não se pode vincular a proteção legal dispensada ao embrião ao instituto da personalidade jurídica, sob pena de tornar-se o embrião in vitro um sujeito de direitos sob todos os aspectos, sejam pessoais ou patrimoniais, porém, totalmente dependente da vontade de terceiros (viúva, médico) para adquirir esta qualidade e os direitos.

Com efeito, embora o pré-embrião ou embrião não possa ser considerado sujeito de direito nos moldes preconizados pelo Código Civil Brasileiro, este é dotado de um valor especial que o distingue de uma simples coisa ou bem, possuindo uma natureza humana, passível, por si só, de proteção pelo ordenamento jurídico.

Do acima exposto, pode-se concluir que o pré-embrião conquanto passível de uma proteção legal, não pode ser um sujeito de direito, e, por conseqüência não possui direitos como o da personalidade - dentre eles, nome, saúde, imagem -, filiação, adoção, sucessão, indenização, etc.

Não é concebível, do ponto de vista jurídico, que a uma das fases do ser humano seja atribuído todos os direitos a que teria o ser humano completo, pois isto geraria uma série de problemas de ordem social, tais como, registrar um pré-embrião com nome e sobrenome dos doadores das células germinais humanas; indenizar um pré-embrião pela sua utilização em desacordo com a Lei de Biossegurança; concorrer na herança com os irmãos, ainda que nascituros ou adultos, dentre outros.

E ainda, há o fato de que existem algumas centenas de embriões excedentários nas clínicas de reprodução humana espalhadas pelo País, e que se não forem utilizados para pesquisas com as células-mãe, fatalmente acabarão sendo descartados, em face da permissão concedida pela nova Lei de Biossegurança, em detrimento de um outro direito 
tão fundamental como a vida, que é a o direito à saúde e dignidade humana. E ressalte-se que, descartar um embrião quer dizer jogar no lixo células-tronco embrionárias que, com o avançar dos estudos e pesquisas, podem ser a chave de uma sobrevida, ou mais, de uma vida longa e saudável.

Por fim, em um país em que se permite "a pílula do dia seguinte", a qual elimina o produto da concepção evitando que ocorra a nidação e existência de um ser humano, com a finalidade única de eliminar uma gravidez indesejada, numa espécie de aborto legalizado (em se adotando a Teoria da Concepção), não vemos óbice na utilização de células-tronco embrionárias, cujo único fim é o de salvar vidas ou permitir-Ihes uma condição digna.

O que não se concebe é a clonagem dos embriões, ainda que para fins terapêuticos, ou a sua concepção com o fim único e exclusivo de experimentos científicos, mas a doação desses embriões que sobejam criopreservados nas clínicas de reprodução humana assistida, por aqueles casais que já realizaram o intento da maternidade e paternidade, é muito mais que uma contribuição científica, é um verdadeiro ato de amor que visa salvar a vida do seu semelhante. Assim como quem retira um órgão do seu corpo e doa para algum ente querido, aquele que doa o pré-embrião, está doando também um órgão e devolvendo a vida à outra pessoa, haja vista que estas células têm a capacidade se transformar em qualquer órgão ou tecido, possibilitando a regeneração e cura de doenças e lesões.

\subsection{Direito comparado}

No Brasil, a partir da edição da Lei de Biossegurança (ZATS, 2007), as pesquisas com células-tronco embrionárias passaram a ser liberadas, desde que sejam utilizados embriões excedentários, cujo destino seria o descarte.

Todavia esse tema no direito alienígena não é pacífico. A maioria dos países não aceita o uso de células-tronco embrionárias como fonte de pesquisa para tratamentos terapêuticos de vanguarda (JÚNIOR, 2007), como ocorre em Portugal, na Alemanha e na França (WELTER, 2006).

A Inglaterra, na contra-mão da posição majoritária dos países europeus é a única que admite não só a utilização das células-tronco embrionárias excedentes, como também a clonagem de embriões para fins de pesquisa científica, o que é condenável não só pelas religiões, mas também por grupos éticos. 
O Brasil, por sua vez, com edição da Lei de Biossegurança passou a fazer parte de um pequeno e seleto grupo de países (Japão, Finlândia, Dinamarca, dentre outros) que, embora condenem e proíbam a clonagem reprodutiva ou até mesmo a terapêutica, admite a utilização destas células, desde que sobressalentes, para o uso em pesquisas científicas.

\section{Reflexos do jurídico}

Por derradeiro, tem-se que a utilização das células-tronco não possui reflexos apenas no âmbito civil, mas também nas áreas administrativa e penal.

No âmbito administrativo, o controle é feito pela Comissão Técnica Nacional de Biossegurança - CTNBio e seus respectivos órgãos, bem como pelos conselhos que fiscalizam as profissões na área de ciências biológicas, como o Conselho Federal de Medicina (através de Resoluções ${ }^{19}$ ), sendo que pela violação destes preceitos e pelos danos provocados, respondem os agentes independentemente de culpa (responsabilidade objetiva), sendo-lhes imputados no Art. 21 do capítulo VII da Lei n.o 11.105/2005, diversas sanções pelas transgressões praticadas.

No aspecto criminal a Lei de Biossegurança, traz em seu capítulo VIII, 06 (seis) artigos contendo condutas que são consideradas crime e apenadas com prisão e multa, dentre elas, a utilização do embrião em desacordo com o disposto no Art. 5.ํ da aludida Lei (Art. 24) e a proibição da clonagem humana (At. 26).

\section{Conclusão}

Assim, em um primeiro momento é necessário ter em mente que ao se posicionar por um dos critérios de início da vida, estará se atribuindo ou não direitos às células-tronco, tais como direito à vida, integridade, dignidade, filiação, sucessão indenização, dentre outros.

Partindo-se do pressuposto de que a vida se inicia com a fecundação, o préembrião, assim como este, independente da implantação e de vir a se tornar uma pessoa (expectativa de ser humano e de nascer vivo), as células-mãe embrionárias seriam sujeitos de direitos e obrigações, e como tal seriam portadoras dos direitos supracitados, consistindo

19 Resolução n.o 1.358/92, do Conselho Federal de Medicina. 
a sua destruição em uma espécie de aborto, condenado não só sob a ótica do direito criminal, mas também, sob o aspecto religioso, moral e ético.

Em sentido contrário, considerando-se outros critérios, ter-se-ia a classificação destas apenas como um conjunto de células passíveis de manipulação, e não um ser humano em desenvolvimento, não sobejando os direitos acima mencionados, a não ser o de uma possível indenização por danos decorrentes, em tese, pela falta de consentimento dos doadores, ou outra causa compatível com este direito.

Todavia, a despeito das controvérsias existentes, o fato é que os pré-embriões, portadores das células-tronco embrionárias não podem ser considerados seres humanos, mas apenas uma das fases deste - o qual somente se completará pelo nascimento com vida, e nesse contexto, os excedentes devem ser utilizados em pesquisas e experimentos científicos, desde que obedecidos os ditames do ordenamento jurídico vigente e os regramentos dos Conselhos de Ética e órgãos afins, com finalidade exclusivamente altruísta, condenando-se e penalizando toda e qualquer forma de comercialização dos mesmos, nos mesmos moldes preconizados pela Lei de Transplante de Órgãos e Tecidos ${ }^{20}$.

\section{Referências}

ALARCÓN, Pietro de Jesús Lora. Patrimônio genético humano e sua proteção na Constituição Federal de 1988. São Paulo: Método, 2004.

AZEVEDO, Marco Antônio oliveira de. Embriões e células-tronco embrionárias têm direito à vida? Universidade do Rio Grande do Sul. Disponível em:

<http://www.cfh.ufsc.br/ethic@/etesp1.pdf>. Acesso em: 24 set. 2006.

BRASIL. Constituição da República Federativa do Brasil. Brasília, DF: Senado Federal, 1988.

BRASIL. Lei n. 11.105, de 24 de março de 2005. Regulamenta os incisos II, IV e V do § 1o do art. 225 da Constituição Federal, estabelece normas de segurança e mecanismos de fiscalização de atividades que envolvam organismos geneticamente modificados - OGM e seus derivados, cria o Conselho Nacional de Biossegurança - CNBS, reestrutura a Comissão Técnica Nacional de Biossegurança - CTNBio, dispõe sobre a Política Nacional de Biossegurança - PNB, revoga a Lei no 8.974, de 5 de janeiro de 1995, e a Medida Provisória

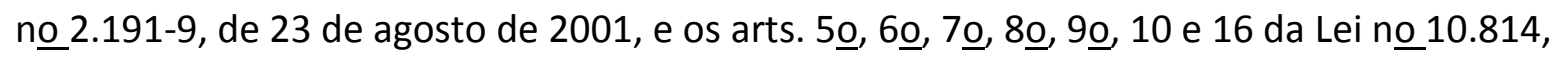
de 15 de dezembro de 2003, e dá outras providências. Disponível em:

<http://www.planalto.gov.br>. Acesso em: 20 set. 2006.

20 Lei 9.434, de 04 de fevereiro de 1997. 
BRASIL. Resolução do Conselho Federal de Medicina n. 1.358, de 11 de novembro de 1992. Adota NORMAS ÉTICAS PARA A UTILIZAÇÃO DAS TÉCNICAS DE REPRODUÇÃO ASSISTIDA, anexas à presente Resolução, como dispositivo deontológico a ser seguido pelos médicos. Disponível em: <http://www. planalto.gov.br>. Acesso em: 30 nov. 2006.

CIENTISTAS fecundam óvulos sem usar espermatozóides. G1.globo.com/Notícias, em 04 de novembro de 2006. Disponível em: <http://g1.globo.com/Noticias/Ciencia/0,_AA13383635603,00.html>. Acesso em: 05 nov. 2006.

DINIZ, Maria Helena. Curso de direito civil brasileiro, v.1: teoria geral do direito civil. 19. ed. São Paulo: Saraiva, 2002.

GONÇALVES, Carlos Roberto. Direito civil: parte geral. 13. ed. São Paulo: Saraiva, 2006. v. 1.

INSTITUTO NACIONAL DE CÂNCER. Banco de sangue de cordão umbilical e placentário (BSCUP). Disponível em: <http://www.inca.gov.br/conteudo_view.asp>. Acesso em: 12 fev. 2007.

JÚNIOR, Dr. Hugo Fernandes. Consultoria legislativa: pesquisa de células-tronco, criação de bancos de sangue de cordão umbilical e placentário. Brasília: Câmara dos Deputados. 2004. Disponível em:

<http://www2.camara.gov.br/publicacoes/estnottec/tema19/2004_10317.pdf>. Acesso em: 13 fev. 2007.

KRELL, Olga Jubert Gouveia. Reprodução humana assistida e filiação civil: princípios éticos e jurídicos. Curitiba: Juruá, 2006.

LEMES, Ana Maria Nogueira; CREPALDI, Joaquim Donizete. A Lei do Biocrime. Lei no 11.105/2005. Jus Navigandi, Teresina, v. 9, n. 795, 6 set. 2005. Disponível em: <http://jus2.uol.com.br/doutrina/texto.asp?id=7243>. Acesso em: 24 set. 2006.

MACHADO, Alberto Vellozo. A lesão aos direitos da personalidade. Direito e Sociedade: Revista do Ministério Público do Estado do Paraná, Curitiba: CEAF, v. 2, n. 1.

MEIRELLES, Jussara Maria Leal de. Filhos da reprodução assistida. In: PEREIRA, Rodrigo da Cunha. (Org.). Família e Cidadania: o novo CCB e a "vacatio legis". Belo Horizonte: IBDFAM/Del Rey, 2002, v. 1. . A vida humana embrionária e sua proteção jurídica. Rio de Janeiro: Renovar, 2000. . Reprodução humana assistida e exame de DNA: implicações jurídicas. Curitiba:

Gênesis, 2004. 
MINAHIM, Maria Auxiliadora. Direito Penal e biotecnologia. São Paulo: RT, 2005. (Série Ciência do Direito Penal Contemporânea; v. 8).

MYSZCZUK, Ana Paula. Genoma humano: limites jurídicos à sua manipulação. Curitiba: Juruá, 2005.

NICOLAU JÚNIOR, Mauro. Inseminação artificial, clonagem do ser humano e sexualidade. Os efeitos produzidos na família, do presente e do futuro. O necessário olhar ético ante os direitos fundamentais e os princípios constitucionais. Jus Navigandi, Teresina, v. 10, n. 884, 4 dez. 2005. Disponível em: <http://jus2.uol.com.br/doutrina/texto.asp?id=7619>. Acesso em: 24 set. 2006.

PEREIRA, Lygia. Clonagem terapêutica... e polêmica. Disponível em: <http://www.comciencia.br/reportagens/celulas/10.shtml>. Acesso em: 24 set. 2006.

PRADO. Luiz Regis. Direito penal do ambiente. São Paulo: RT, 2005.

PRESIDÊNCIA DA REPÚBLICA FEDERATIVA DO BRASIL: Banco de dados. Disponível em: $<$ http://www.planalto.gov.br>. Acesso em: 21 set. 2006.

RASKIN, Salmo. Uma Discussão a favor da vida. Instituto Ciência e Fé promove debate sobre o tema. Disponível em: <www.cienciaefe.org.br/jornal/e69/Mt01.htm>. Acesso em: 22 out. 2006.

REGIS, Arthur Henrique de Pontes. Início da vida humana e da personalidade jurídica: questões à luz da Bioética. Jus Navigandi, Teresina, v. 9, n. 617, 17 mar. 2005. Disponível em: <http://jus2.uol.com.br/doutrina/texto.asp?id=6462>. Acesso em: 24 set. 2006.

ROXIN, Claus. A proteção da vida humana através do Direito Penal. Conferência realizada no dia 07 de março de 2002, no encerramento do Congresso de Direito Penal em Homenagem a Claus Roxin, Rio de Janeiro. Disponível em: <www.mundojuridico.adv.br/sis_artigos/artigos.asp?codigo>. Acesso em: 22 out. 2006.

SARTORI, Ivan Ricardo Garisio. Célula-tronco. O direito. Breves considerações. Jus Navigandi, Teresina, v. 9, n. 781, 23 ago. 2005. Disponível em:

<http://jus2.uol.com.br/doutrina/texto.asp?id=7186>. Acesso em: 24 set. 2006.

SEGRE, Marco. A propósito da utilização de células-tronco. Disponível em:

<http://www.comciencia.br/reportagens/celulas/11.shtml>. Acesso em: 24 set. 2006.

SOCIEDADE BENEFICENTE ISRAELITA BRASILEIRA - HOSPITAL ALBERT EINSTEIN. Banco de sangue de cordão umbilical. Disponível em: <http://www.einstein.br/concham. aspx?ic=37\&id=44\&id1=38>. Acesso em: 12 fev. 2007. 
TARIFA, Rita de Cássia Resquetti; FERRARO, Valkiria Lopes. Autonomia Corporal e Manipulação Genética. Revista Scientia luris, Revista do Curso de Mestrado em Direito Negocial da UEL, Londrina, v. 9, 2005.

WELTER, Larissa Cristine Machado. A regulamentação internacional do uso de células-tronco embrionárias obtidas pela clonagem terapêutica . Jus Navigandi, Teresina, v. 9, n. 604, 4 mar. 2005. Disponível em: <http://jus2.uol.com.br/doutrina/texto.asp?id=6397>. Acesso em: 24 set. 2006.

ZATS, Mayana. Ético ou não ético: como decidir? Centro de Estudos do Genoma Humano. Disponível em: <http://genoma.ib.usp.br/pacientes_etico.php>. Acesso em: 13 fev. 2007. 
